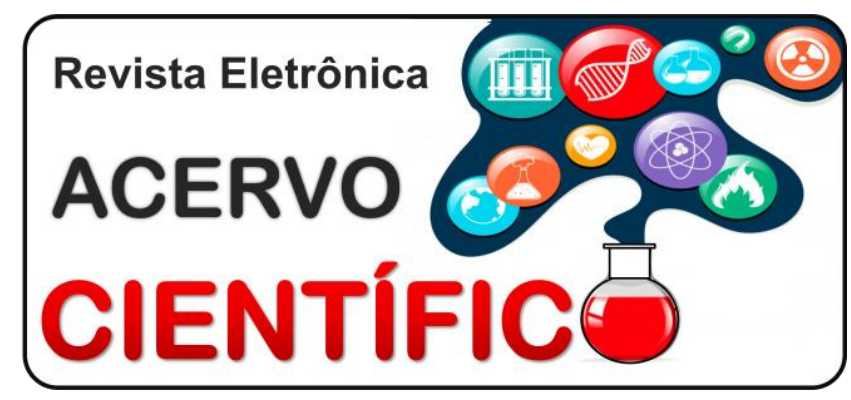

\section{ARTIGO ORIGINAL}

Recebido em: 1/2020

Aceito em: 1/2020

Publicado em: 2/2020

\title{
Análise bacteriológica das barras de apoio dos ônibus utilizados no transporte público da cidade de Macapá-Amapá
}

\author{
Bacteriological analysis of bus support bars used in public transport of Macapá-Amapá city
Análisis bacteriológico de las barras de apoyo de autobuses utilizadas en el transporte público de la ciudad de Macapá-Amapá

Rodrigo Almeida de Souza ${ }^{1}$, Claude Porcy ${ }^{1}$, Rubens Alex de Oliveira Menezes ${ }^{2 *}$.

\begin{abstract}
Resumo: Esse artigo buscou identificar os tipos de bactérias encontradas nas barras de apoio dos ônibus pertencentes ao sistema de transporte público da cidade de Macapá - AP, e assim, mapear, dentre as rotas pesquisadas, os veículos que apresentarem maior índice de contaminação bacteriana. Foram coletadas amostras de 10 ônibus e micro-ônibus da cidade e cultivadas para averiguação das espécies bacterianas ali presentes, após esse processo, foram realizados testes bioquímicos para a diferenciação das mesmas. Adicionalmente, foram encontradas, em (85\%) das mostras bactérias da espécie Staphylococcus aureus, em menor ocorrência (15\%) a espécie Staphylococcus epidermidis além de serem encontrados Bacilos Gram-Negativos não fermentadores (20\%) presentes naturalmente no meio ambiente e em (5\%), uma enterobactéria de interesse médico identificada como Serratia liquefaciens. O estudo demonstrou a presença de bactérias colonizando as barras de apoio dos ônibus evidenciando que são ambientes favoráveis para a disseminação de bactérias patogênicas. Assim, se torna indispensável que se adotem medidas de higienização mais eficazes para os veículos além de alertar a comunidade sobre a importância da higienização e lavagem das mãos após o uso do serviço.
\end{abstract}

Palavras-chave: Microbiologia, Contaminação, Veículo.

\begin{abstract}
This article aimed to identify the types of bacteria found in bus support bars belonging to the public transport system of the city of Macapá - AP, and thus, map, among the surveyed routes, the vehicles with the highest rate of bacterial contamination. Samples were collected from 10 city buses and minibuses and cultivated to verify the bacterial species present there. After this process, biochemical tests were performed to differentiate them. Additionally, in $85 \%$ of the samples of the bacteria Staphylococcus aureus, lesser $(15 \%)$ of the species Staphylococcus epidermidis were found. In addition, non-fermenting gram-negative bacilli $(20 \%)$ were found naturally in the environment and in (5\%), an enterobacterium of medical interest identified as Serratia liquefaciens. The study showed the presence of bacteria colonizing the bus bars, showing that they are favorable environments for the spread of pathogenic bacteria. Thus, it is indispensable to adopt more effective cleaning measures for vehicles and to alert the community about the importance of hand hygiene and washing after using the service.
\end{abstract}

Keywords: Microbiology, Contamination, Vehicle.

1 Faculdade Estácio de Macapá, Macapá (AP), Brasil.

2 Universidade Federal do Amapá (UNIFAP), Macapa (AP), Brasil. *E-mail: rubens.alex@unifap.br 
Resumen: Este artículo tuvo como objetivo identificar los tipos de bacterias que se encuentran en las barras de apoyo de autobuses que pertenecen al sistema de transporte público de la ciudad de Macapá - AP y, por lo tanto, mapear, entre las rutas encuestadas, los vehículos con la mayor tasa de contaminación bacteriana. Se recogieron muestras de 10 autobuses urbanos y minibuses y se cultivaron para verificar las especies bacterianas presentes allí. Después de este proceso, se realizaron pruebas bioquímicas para diferenciarlas. Además, en el $85 \%$ de las muestras de la especie Staphylococcus aureus, se encontraron menos (15\%) de la especie Staphylococcus epidermidis. Además, los bacilos gramnegativos no fermentadores $(20 \%)$ se encontraron naturalmente en el medio ambiente y en (5\%), una enterobacteria de interés médico identificada como Serratia liquefaciens. El estudio mostró la presencia de bacterias que colonizan las barras colectoras, lo que demuestra que son ambientes favorables para la propagación de bacterias patógenas. Por lo tanto, es indispensable adoptar medidas de limpieza más efectivas para los vehículos y alertar a la comunidad sobre la importancia de la higiene y el lavado de manos después de usar el servicio.

Palabras clave: Microbiología, Contaminación, Vehículo

\section{INTRODUÇÃO}

Os microrganismos são encontrados nos mais variados ambientes e estão presentes em quase todos os lugares do planeta, em sua maioria não causam malefícios sendo considerados patogênicos apenas $3 \%$ de todo seu leque de espécies (GOMES NCP, et al., 2016). Dentre estes, os mais comuns são as bactérias, organismos que vivem em uma relação de mutualidade e comensalidade com os seres humanos estando presentes em sua microbiota natural ajudando na digestão dos alimentos, na proteção contra outros microrganismos e produzindo substâncias benéficas para a regulação e funcionamento do corpo (CORDEIRO PMD, et al., 2017).

Em contra partida, é a população que apresenta o maior número de espécies patogênicas e que podem desencadear doenças de duas maneiras distintas, por infecção, sendo esta a causa mais comum de doenças e óbitos principalmente em locais onde há pouco ou nenhum saneamento básico, ou produzindo substâncias tóxicas (GOMES NCP, et al., 2016). Diversos microrganismos possuem a capacidade de adaptação em diversos ambientes, sobrevivendo e multiplicando-se e sendo transferidos para um novo hospedeiro (AMORIM AR, et al., 2017).

Existem várias maneiras das bactérias adentrarem o organismo como por via oral, nasal, inoculadas por picadas de insetos e agulhas, relações sexuais e feridas expostas, mas só desencadearam um processo infeccioso em condições de desequilíbrio fisiológico onde o organismo infectado pode apresentar barreiras naturais do corpo rompidas, um sistema imune inapto ou ineficiente ou também quando o microrganismo etiológico apresenta uma gama extensa de mecanismos de virulência (GOMES NCP, et al., 2016; FERNANDES AAL, et al., 2012).

A presença de microrganismos bacterianos em superfícies de ambientes domiciliares e domésticos demonstra que qualquer tipo de ambiente está suscetível a contaminação estando relacionados diretamente com a higiene do mesmo, assim sendo, objetos que são manipulados por várias pessoas mesmo sendo de um grupo restrito possibilitam a transferência destes germes para organismos enfraquecidos gerando neles patologias. Percebe-se então a relação entre infecção e superfícies de objetos e lugares contaminados, sendo as mãos o principal veículo de carreamento dos microrganismos das superfícies para o interior do organismo humano (SILVA MHR, et al., 2014).

Logo, a aferição da presença de microrganismos nos apoios internos dos veículos pertencentes ao transporte público se faz importante por este ser um ambiente com grande fluxo e aglomeração de pessoas o que pode resultar no aumento da transmissão de doenças infecciosas em indivíduos saudáveis e mais ainda em imunocomprometidos. A principal medida para reduzir as chances de se adquirir uma infecção relacionada a superfícies contaminadas é a higienização correta das mãos, um pequeno ato que pode evitar surtos causados por enterobactérias, por exemplo, sendo estas intimamente relacionadas à falta da prática de lavar as mãos (CORDEIRO PMD, et al., 2017). 
As mãos albergam uma microbiota altamente diversificada, tanto quantitativamente como qualitativamente, atuando como veículo de agentes microbianos, essa troca microbiológica entre indivíduos e fômites pode facilitar a ocorrência e disseminação de doenças infecciosas, contribuindo para que o contato com as mãos em veículos do sistema de transporte público coletivo sejam potenciais fontes ambientais de patógenos para os seus usuários (NEVES LS, 2016).

Sabe-se que algumas bactérias possuem a capacidade de produzir diversos fatores de virulência, como a capacidade de adesão a diversas superfícies bióticas e abióticas formando biofilmes. Esses biofilmes se tornam em importantes reservatórios de patógenos, que são adquiridos de diversas formas pelos indivíduos, como os usuários dos ônibus de transporte público. Além disso, a produção de fatores de virulência tem contribuído para a resistência e proteção contra mecanismos de defesa do hospedeiro (AMORIM AR, et al., 2017).

O contato com objetos e superfícies contaminados por bactérias não necessariamente representa riscos à saúde. O desencadeamento de infecção depende de fatores como a virulência da espécie contaminante, capacidade que as bactérias possuem de multiplicar e prejudicar o organismo; carga microbiana e da integridade imunológica do indivíduo (SILVA LB, et al., 2010).

É cada vez maior o número de pessoas com sistema imunológico debilitado na sociedade, sendo representado por idosos, pessoas com doenças crônicas e degenerativas, transplantados, hemodialisados, com utilização de dispositivos permanentes ou que realizam tratamento médico domiciliar (SILVA LB, et al., 2010; NEVES LS, 2016). O aumento do grupo "de risco" na comunidade demonstra a necessidade de caracterização dos objetos e superfícies do ambiente como importantes na compreensão das múltiplas rotas de disseminação de bactérias.

No Brasil existem poucos dados sobre fômites presentes nos sistemas de transportes públicos coletivos, principalmente estudos que evidenciam a presença de microorganismos nesses transportes. Essas informações poderiam auxiliar na redução da disseminação de patógenos, principalmente os patogênicos, além de fornecer bases epidemiológicas para monitoração e controle dos mesmos. Nesse contexto, o presente artigo visa identificar os tipos de bactérias encontradas nas barras de apoio dos ônibus pertencentes ao sistema de transporte público da cidade de Macapá - AP no ano de 2018 e assim mapear, dentre as rotas pesquisadas, os veículos que apresentarem maior índice de contaminação bacteriana.

\section{MÉTODOS}

Trata-se de um estudo de caráter analítico-descritivo, onde desenvolveu-se a avaliação quantitativa dos parâmetros microbiológicos na identificação de bactérias presentes no transporte público da cidade de Macapá-AP, no ano de 2018, realizado perante consentimento e autorização por escrito da empresa de transporte público atuante nesta região.

As coletas foram feitas nos ônibus e micro-ônibus que circulam nas quatro zonas geográficas (norte, sul, leste e oeste) da cidade de Macapá sendo realizadas em 10 veículos diferentes, sendo duas amostras por veículo totalizando-se assim 20 amostras. Para uma maior abrangência nas coletas e pela probabilidade de contato dos passageiros com as barras de apoio dos ônibus, as coletas foram direcionadas em dois locais diferentes em seu interior, nos apoios das portas de entrada e nas barras de apoio centrais.

As coletas foram realizadas com auxílio de swab estéril, previamente umedecido em solução salina $(\mathrm{NaCl})$, Em seguida, o swab foi inoculado em caldo de enriquecimento Brain Heart Infusion (BHI), e encaminhado ao Laboratório de microbiologia da Faculdade Estácio de Macapá. Os tubos contendo o caldo de enriquecimento foram incubados em estufa microbiológica a uma temperatura de $35 \pm 1^{\circ} \mathrm{C}$ por 24 horas.

Após o período de incubação, as amostras foram semeadas pela técnica de esgotamento nas placas de Petri contendo os meios de cultura sólidos Ágar Cled e Ágar MacConckey, para obtenção de colônias isoladas. O Ágar Cled é um meio diferencial e enriquecido, já o Ágar MacConckey, é um meio seletivo e diferencial para bactérias Gram negativas. As placas foram incubadas na estufa a $35 \pm 1^{\circ} \mathrm{C}$ por 24 horas e passado este tempo de incubação, as colônias foram submetidas à análise macroscópica e coradas através 
da coloração de Gram para identificação microscópica da morfologia e propriedade tintorial das bactérias, para a partir de então, serem realizadas as provas bioquímicas de identificação das espécies isoladas.

A identificação bioquímica das bactérias foi realizada de acordo com as características microscópicas observadas na coloração de gram. Com as colônias Gram negativas isoladas em Agar MacConkey realizouse a prova da detecção da enzima oxidase e fermentação de açúcar usando-se o meio Triple Sugar Iron (TSI). As que foram oxidase negativa e fermentaram a glicose, foram identificadas por meio de provas bioquímicas para enterobacterias com o uso dos meios bioquímicos denominados: Escola Paulista de Medicina (EPM), Motilidade, Indol e Lisina (MILI) e CITRATO.

Em contrapartida, as colônias oxidase positivas e não fermentadoras foram identificadas somente como bactérias Não Fermentadoras que se encontram normalmente no meio ambiente. No que diz respeito às colônias isoladas em Agar Cled, realizou-se a identificação dos cocos Gram positivos, estes foram identificados por meio da prova da catalase, manitol, coagulase e sensibilidade a novobiocina para a diferenciação das espécies de Staphylococcus.

Estes dados foram organizados em tabelas e planilhas usando como ferramenta o Microsoft Excel, versão $2010 \AA$, com cálculos das frequências absolutas e relativas, o que possibilitou a construção de tabela e gráfico. Para o presente artigo foi solicitado à dispensa do consentimento livre e esclarecido, pois o projeto não utilizou de pesquisa com seres humanos e/ou animais, sendo submetidos ao comitê de ética, para obtenção do protocolo de isenção.

\section{RESULTADOS E DISCUSSÃO}

De 10 ônibus e um total de 20 amostras, todas se mostraram positivas na análise microbiológica apresentando crescimento de um ou mais microrganismos de origem bacteriana. As coletas priorizaram os locais de maior contato com os usuários do transporte público, com o intuito de evidenciar o local de maior risco de contaminação à população e os possíveis tipos bacterianos encontrados.

$\mathrm{Na}$ (Tabela 1), observa-se que a bactéria Staphylococcus aureus se apresenta em 17 amostras analisadas e também aponta a presença de Serratia liquefaciens, uma enterobacteria presente no meio ambiente que também é oriunda de contaminação fecal, além da presença de outras bacilos gram negativo não fermentadoras de glicose que ocorrem naturalmente na natureza. Observa-se ainda que os veículos de número 6 e 10 apresentaram uma variedade de germes isolados o que sugere uma maior contaminação.

Tabela 1 - bactérias encontradas nas barras de apoio de 10 ônibus pertencentes à frota de transporte público da cidade de Macapá-AP.

\begin{tabular}{ccc}
\hline Ônibus & Espécies das barras de apoio das entradas & Espécies nas barras de apoio centrais \\
\hline 1 & Staphylococcus aureus & Staphylococcus aureus \\
2 & Staphylococcus aureus & Staphylococcus aureus \\
3 & Staphylococcus aureus & Staphylococcus aureus \\
4 & Staphylococcus aureus & Staphylococcus epidermidis \\
5 & Staphylococcus aureus & Staphylococcus aureus \\
6 & Staphylococcus epidermidis / Serratia liquefaciens & Staphylococcus aureus \\
7 & Staphylococcus aureus / BGN Não Fermentadores & Staphylococcus aureus \\
8 & Staphylococcus aureus / BGN Não Fermentadores & Staphylococcus aureus \\
9 & Staphylococcus aureus & Staphylococcus aureus \\
10 & Staphylococcus epidermidis / BGN Não & Staphylococcus aureus / BGN Não \\
\end{tabular}

Fonte: Souza RA, et al., 2018.

REAC/EJSC | Vol. 8 | e2937 | DOI: https://doi.org/10.25248/reac.e2937.2020 
$\mathrm{Na}$ (Figura 1), observamos o percentual destes microrganismos isolados, apresentando 0 Staphylococcus aureus como sendo a espécie com a maior frequência (85\%), tanto nas barras de apoio localizadas na entrada, como nas que ficam no meio do veículo, mostrando assim a distribuição quase que total e igualitária desta bactéria no interior ônibus. A contaminação em todas as superfícies de contato com as mãos analisadas atesta o potencial dos veículos e demais superfícies da via, como fontes de disseminação de importantes patógenos como o S. aureus (NEVES LS, 2016).

No Brasil, alguns estudos têm revelado que os ônibus de transporte público coletivo podem estar contaminados por diferentes tipos de microorganismos, como bactérias, fungos e até parasitos intestinais (NEVES LS, 2016). Adicionalmente, foi observado poucas referências que abordam a contaminação de superfícies por $S$. aureus em ambientes comunitários, essa escassez de trabalhos e dados no país limita a confrontação e comparabilidade dos resultados.

Figura 1 - Porcentagem do crescimento bacteriano nas amostras analisadas.

\begin{tabular}{|c|c|c|c|c|c|}
\hline \multirow{2}{*}{\multicolumn{2}{|c|}{ 욜 $80 \%$}} & $85 \%$ & & \\
\hline & & & & & \\
\hline $\bar{\Xi}$ & $70 \%$ & & & \multicolumn{2}{|c|}{ Bacilos Gram Negativos } \\
\hline d & $50 \%$ & & & & \\
\hline$\overline{0}$ & $50 \%$ & & & & \\
\hline$\frac{0}{0}$ & $40 \%$ & & & & \\
\hline ד্ত & $30 \%$ & & \multirow[b]{2}{*}{$15 \%$} & $20 \%$ & \\
\hline تِ & $20 \%$ & & & & \\
\hline U్ & $10 \%$ & & & & $5 \%$ \\
\hline & $0 \%$ & $\begin{array}{c}\text { Staphylococcus } \\
\text { aureus }\end{array}$ & $\begin{array}{l}\text { Staphylococcus } \\
\text { epidermidis }\end{array}$ & $\begin{array}{c}\text { BGN Não } \\
\text { Fermentadores }\end{array}$ & $\begin{array}{c}\text { Serratia } \\
\text { liquefaciens }\end{array}$ \\
\hline
\end{tabular}

Fonte: Souza RA, et al., 2018.

É importante destacar que a grande diferença de prevalência microbiológica encontrada entre os diversos estudos pode ser reflexo de diversos fatores, como a metodologia de amostragem, o tamanho da amostra, frequência com que os ônibus são higienizados e da própria população. A literatura existente é inconsistente e incompleta a respeito de um método ótimo para detectar $S$. aureus de superfícies ambientais. Não existe uma metodologia padronizada para realização de coleta em superfícies inanimadas (HOGAN PG et al. 2015). Os trabalhos citados usaram técnicas diferentes para coleta de amostras, o que pode refletir no resultado obtido.

Diversos estudos afirmam que, vários objetos de uso cotidiano como, por exemplo, aparelhos celulares, moedas, cédulas de dinheiro, canetas e brinquedos podem servir como reservatório para microrganismos (GOMES TM, et al., 2014). Para Silva MHR, et al. (2014), vários tipos de microrganismos bacterianos foram isolados em superfícies de mouses e teclados dos computadores da Universidade de Três lagoas - MS, a maioria dos germes encontrados foram bacilos Gram-negativos pertencentes à família das enterobacterias como Escherichia coli e Proteus spp. E cocos Gram-positivos sendo eles Staphylococcus spp. e Streptococcus spp.

No transporte público a disseminação das bactérias ocorre através de seus usuários que provém de vários lugares distintos como, ambientes hospitalares e postos de saúde, locais onde há manipulação de alimentos, água e solo que podem estar contaminados, repassando assim estes germes para as superfícies de contato mais comuns do ambiente, como alças e balaústres de apoio (LIMA LR, 2014; AMORIM AR, et al., 2017). Em pesquisas da mesma natureza realizadas por Cordeiro PMD, et al. (2017), Fernandes AAL, et 
al. (2012) e Lima LR, et al. (2014), as bactérias mais comuns de serem encontradas são as que fazem parte da própria microbiota natural do corpo humano sendo a mais frequente Staphylococcus aureus e em menor incidência Staphylococcus epidermidis.

A espécie Staphylococcus aureus, presente principalmente nas fossas nasais e na superfície cutânea dos recém-nascidos, é um importante germe de interesse médico por apresentar resistência razoável à dessecação e ao frio o tornando viável em superfícies de objetos inanimados por longos períodos (SANTOS AL, et al., 2007). Seus mecanismos de virulência o permitem causar doenças por invasão direta dos tecidos, adentrando-os por meios de feridas ou ingestão oral, e por produção de toxinas.

Em crianças, causa a síndrome da pele escaldada, uma dermatite esfoliativa bolhosa com aparência de queimadura sendo dado o nome de impetigo bolhoso a forma localizada dessa doença, também é responsável por intoxicação através de alimentos contaminados que causam vários sintomas sendo eles vomito grave, diarreia aquosa, dor abdominal podendo ser acompanhada de sudorese e cefaleia sem febre estando associada a casos de desidratação severa pele perda abrupta de fluídos (SANTOS AL, et al., 2007; MURRAY PR, 2009).

Dentre outros cocos Gram-positivos que povoam a pele humana está presente o Staphylococcus epidermidis, considerado de baixa virulência, sua capacidade de causar infecções está ligada principalmente a adesão aos tecidos através de moléculas e estruturas chamadas de adesinas e na formação de biofilmes, estes se aderem com grande facilidade as superfícies propiciando assim o processo patológico infeccioso (BRATFICH OJ, 2005; TRABULSI JR, 2008; THEISEN J, 2010).

Em sua pesquisa realizada na cidade de Curitiba-PR, Rodrigues APC et al. (2006) relatou a presença de Serratia liquefaciens em $40 \%$ de suas amostras, evidenciando um alto índice de ocorrência desta bactéria na região. Esse microorganismo pertence à família das enterobacterias e sua ocorrência é mais rara em casos clínicos não deixando de ser uma bactéria de extremo interesse médico ligada principalmente a casos de infecção hospitalar (TAVARES AR, 2016).

É importante destacar que a Serratia liquefaciens está associada principalmente a infecções urinarias de pacientes imunodeprimidos apresentando uma alta taxa de resistência a antibióticos além de produzir enzimas como lipase, gelatinase e Dnase, sendo estas características, atualmente considerada uma bactéria emergente causadora de infecções hospitalares graves (MENEZES EA, et al., 2004).

Há ainda os bacilos Gram-negativos não fermentadores, essas bactérias apesar de se fazerem presentes no meio ambiente de maneira natural, estão intrínsecamente ligadas a infecções nosocomiais, dentre estas, as que se evidenciam com maior frequência são as bactérias dos gêneros Pseudomonas spp., Acinetobacter spp. e Achromobacter spp. Sua importância se dá pela resistência que apresentam, propiciando assim vários sítios infeciosos distintos onde se instalam podendo ser isoladas em vários tipos de materiais biológicos como aspirado traqueal, escarro, urina, lavado bronco alveolar, sangue, secreção de ferida operatória, secreção abdominal e ponta de cateter (DELIBERALI B, et al., 2011; PEREIRA CAS, et al., 2017).

Outro detalhe que deve ser considerado em estudos dessa natureza é a classificação do grau de contaminação de superfícies, como as dos ônibus ou outras superfícies que apresenta contato constante com a população, fator de extrema dificuldade de mensuração, visto que ainda não há legislação que determine o nível de contaminação aceitável em locais de acesso público (AMORIM AR, et al., 2017).

A contaminação dos microrganismos encontrados nas barras de ônibus, dividida em contaminantes pertencentes a microbiota normal e agentes que podem ser considerados oportunistas e potencialmente patogênicos. Essa patogenicidade está diretamente relacionada ao status imunológico do hospedeiro infectado, de indivíduos imunologicamente debilitados, através do contato com estes microrganismos (SILVA LB, et al., 2010; AMORIM AR, et al., 2017). Desta forma, as recomendações e orientações acerca da higienização das superfícies dos ônibus, pode contribuir para a redução do índice de contaminação destas superfícies, diminuindo o risco a saúde dos usuários e trabalhadores do transporte público de Macapá. 


\section{CONCLUSÃO}

O presente estudo demonstrou a presença de microrganismos de origem bacteriana colonizando as barras de apoio dos ônibus pertencentes à frota de transporte público da cidade de Macapá-AP, evidenciando que os mesmos são ambientes favoráveis para a disseminação de bactérias patogênicas ligadas diretamente a infecções e doenças graves, principalmente em pessoas imunocomprometidas e em grupos de risco. Por este motivo, se torna indispensável que se adotem medidas de higienização mais eficazes para os veículos bem como alertar a comunidade sobre a presença desses germes e a importância da higienização e lavagem das mãos após o uso do serviço para que se diminua o risco de infecção própria e carreamento de tais bactérias para outros ambientes.

\section{REFERÊNCIAS}

1. AMORIM AR, et al. Condições higiênico-sanitárias, tipos bacterianos e teste de susceptibilidade antimicrobiana em transporte público de uma cidade do alto Paranaíba/MGbrasil. Psicologia e Saúde em debate. 2017:3(1):68-86.

2. BRATFICH OJ. Epidemiologia molecular de staphylococcus epidermidis isolados de infecções de corrente sangüínea em pacientes do hospital das clínicas da UNICAMP. Tese (Doutorado em Ciências Médicas). Faculdade de Ciências Médicas da Universidade Estadual de Campinas. São Paulo. 2005.

3. CORDEIRO PMD, et al. Análise microbiológica de assentos e alça de teto em transportes coletivos da cidade Juazeiro do Norte, Ceará. Revista Interfaces: Saúde, Humanas e Tecnologia. 2017; 4(12): 68-74.

4. DELIBERALI B, et al. Prevalência de bacilos Gram-negativos não fermentadores de pacientes internados em Porto Alegre-RS. Jornal Brasileiro de Patologia e Medicina Laboratorial. 2011; 47(5): .529-534.

5. FERNANDES AAL, et al. Diversidade de bactérias, fungos e formas de resistência de parasitos em duas rotas de ônibus do transporte coletivo da grande Vitória-ES. Vitória: Rev. Sapientia. 2012; 10(11): 39-45.

6. GOMES NCP, et al. Análise da contaminação bacteriológica do setor de parada de ônibus municipais do terminal rodoviário de uma cidade do interior do estado de São Paulo. J. Health Sci. Inst. 2016; 34(3): 140-143.

7. GOMES TM, et al. Pesquisa de enteroparasitas em meios de transporte público urbano da cidade de Patos De Minas Mg-Brasil. Psicologia e Saúde em debate. 2016; 2(1): 74-99.

8. HOGAN PG, et al. Staphylococcus aureus on Fomites. Ann Public Health Res. 2015; 2: 1-8.

9. LIMA LR et al. Análise de enterobacterias de importância clínica em duas rotas do transporte público da cidade de Taguatinga-Df. 2014: 1-9.

10. MENEZES EA, et al. Frequência de serratia sp em infecções urinárias de pacientes internados na santa casa de misericórdia em Fortaleza. Revista da Sociedade Brasileira de Medicina Tropical. 2004; 37(1): 70-71.

11. MURRAY, PR. Microbiologia médica. 6. ed. Rio de Janeiro: Elsevier; 2009. Edição traduzida.

12. NEVES LS. Prevalência, perfil de suscetibilidade e caracterização molecular de Staphylococcus aureus isolados de uma linha de ônibus do sistema de transporte público coletivo do município de Goiânia-GO. Dissertação (Mestrado em Biologia das Relações Parasito-Hospedeiro). Universidade Federal de Goiás. Goiás 2016.

13. PEREIRA CAS, et al. Pesquisa de bacilos gram negativos não fermentadores presente em torneiras de um hospital privado do município de Volta Redonda, RJ. Episteme Transversallis. 2012; 3(1); 1-9.

14. RODRIGUES APC, et al. Levantamento de bactérias, fungos e formas de resistência de parasitos em duas rotas de ônibus do transporte coletivo de Curitiba, Paraná. RUBS, 2006; 2(2): 24-31.

15. SANTOS AL, et al. Staphylococcus aureus: visitando uma cepa de importância hospitalar. Jornal Brasileiro de Patologia e Medicina Laboratorial. 2007; 43(6): 413-423.

16. SILVA LB, et al. Análise bacteriológica comparativa entre aparelhos telefônicos públicos localizados próximos de hospitais e demais localidades da cidade de Uberaba - MG. RBAC. 2010; 42(3):187-190.

17. SILVA MHR, et al. Isolamento e identificação de microrganismos presentes em superfícies de teclados e mouses de uma universidade de Três Lagoas, Ms. Colloquium vitae. 2014; 6(3): 83-90.

18. TAVARES AR. Infecções por Serratia spp. em ambientes de terapia intensiva: uma revisão integrativa. Trabalho de Conclusão de Curso (Enfermagem) - Faculdade de Ceilândia, Universidade de Brasília - UnB. CEILÂNDIA/DF. 2016.

19. THEISEN J. Suscetibilidade de Staphylococcus epidermidis a vancomicina, rifampicina, azitromicina e eritromicina. 2010. Trabalhos de Conclusão de Curso de Graduação (Farmácia) - Universidade Federal do Rio Grande do Sul. Rio Grande do Sul, 2010.

20. TRABULSI JR. Microbiologia. 5. ed. São Paulo: Atheneu, 2008. 